\title{
Non familial juvenile distal spinal muscular atrophy of upper extremity
}

\author{
J B PEIRIS,* K N SENEVIRATNE, $\dagger$ H R WICKREMASINGHE, $\$$ S B GUNATILAKE, \\ R GAMAGE* \\ From the Institute of Neurology* and Department of Pathology $\ddagger$ General Hospital, and Department of \\ Physiology, University of Colombo, † Sri Lanka
}

SUMMARY An uncommon variety of non familial, juvenile onset, spinal muscular atrophy with asymmetric distal upper extremity affection is described. One hundred and two patients with a one to 14 year follow up are analysed. Spinal muscular atrophies with a distal distribution are rare. However, in the past three decades, previously unrecognised varieties of neurogenic muscular atrophy have been described in Asia (Japan, India, Sri Lanka and Singapore) under a variety of names. These provide interesting data for discussion of Asian neurogenic muscular atrophies with distal affection, in the context of diseases of the motor neuron.

Around the same time as the recognition of the proximal spinal muscular atrophy in children and adolescence in the west, ${ }^{12}$ Hirayama $e t a^{\beta}$ in Japan described a predominantly distal form of juvenile muscular atrophy confined to one upper limb. Although rare, over 150 patients with distal spinal muscular atrophy of one upper limb have been described in Japan ${ }^{4-8}$ while distal bilateral upper limb affection has been described in Sri Lanka, asymmetrically ${ }^{9}$ and in India symmetrically. ${ }^{10}$ Spinal muscular atrophy affecting one leg has been seen in India ${ }^{11}$ and neurogenic atrophy affecting all four limbs and bulbar muscles has been described as Madras motor neuron disease. ${ }^{1213}$ While large series of patients with distal spinal muscular atrophy have been described in Asia, only sporadic case reports have appeared from elsewhere. ${ }^{14-17}$

This paper describes 102 young patients with a one to 14 year follow up of relatively benign, localised, distal spinal muscular atrophy confined to the upper limbs, resembling the pure form of progressive muscular atrophy (PMA) of motor neuron disease, but with distinctive features of its own.

\section{Material and methods}

Patients were included in the study if the following criteria were fulfilled: onset before the age of 25 years; insidious onset, slowly progressive weakness and wasting of one or both upper limbs commencing in the hand/s; disease confined to the motor system of the upper limbs without lower limb,

Address for reprint requests: Dr J B Peiris, 58/7 Ward Place, Colombo 7, Sri Lanka

Received 14 June 1988 and in-revised form 7 September 1988. Accepted 12 September 1988 bulbar sensory symptoms or long tract signs; clinical evidence of denervation including fasciculation; electromyographic evidence of denervation in the absence decrease of peripheral motor and sensory nerve conduction; normal cerebrospinal fluid; radiologically normal cervical spine with exclusion of craniospinal anomaly and syringomyelia when indicated by myelography.

Histological evidence corroborative of progressive neurogenic atrophy was obtained in 23 of the first 50 patients but was not looked for in later cases as it did not appear to be necessary in those with the established characteristic clinical profile.

Results

One hundred and two patients fulfilling these criteria

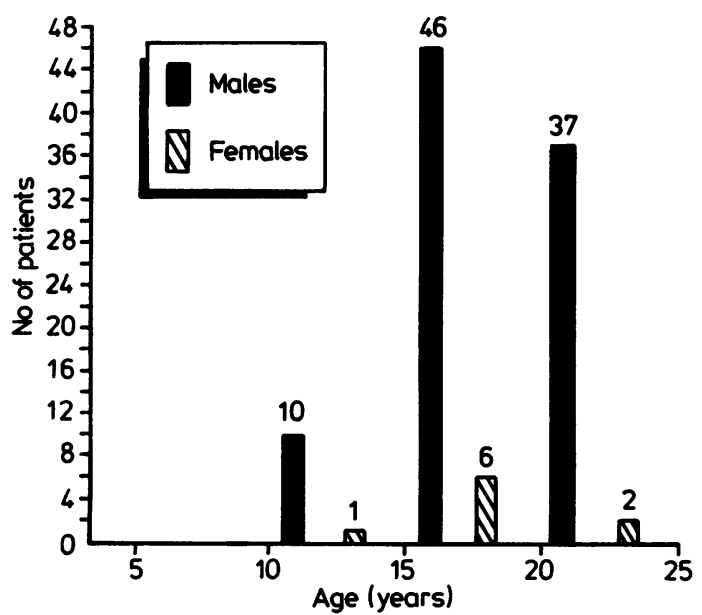

Fig 1 Age and sex distribution at onset. 
Table 1 Distribution of muscle wasting at presentation

\begin{tabular}{lcccc}
\hline & \multicolumn{2}{c}{ Unilateral } & \multicolumn{2}{c}{ Bilateral } \\
& $R$ & $L$ & $R>L$ & $L>R$ \\
\hline C8 T1 only & 4 & 10 & 0 & 0 \\
C7 C8 T1 & 8 & 17 & 0 & 0 \\
C7C8T1 of one & 0 & 0 & 32 & 13 \\
C8 T1 of other & & & & \\
Bilateral C7 C8 T1 & 0 & 0 & 8 & 4 \\
C5-T1 of one & 0 & 0 & 3 & 1 \\
C7C8T1 of other & & & 1 & 0 \\
Bilateral C5-T1 & 0 & 0 & 44 & 19 \\
Total & 12 & 27 & 44 \\
\hline
\end{tabular}

were seen at the Neurology Unit, General Hospital, Colombo over a 15 year period from 1972.

Age, sex and marital status (fig 1)

There was a marked male preponderance with only nine females in this series of 102 patients. At the time of presentation the youngest was aged 13 years and oldest 29 years, while the onset of symptoms occurred from 12 to 25 years, with a peak between 17 and 22 years. Considering the early onset and uncertainty of course and prognosis it was not surprising to find that only six patients were married.

\section{Family history}

There was no familial incidence of this disease or any other neurological, muscular or skeletal disease. There was no relationship to intranatal maternal infection or sibship.

\section{Presenting complaints}

In all patients, the symptoms were unilateral at onset. At time of presentation symptoms were unilateral in $39(38 \cdot 2 \%)$. In those with bilateral affection at the time of presentation, there was marked asymmetry of muscle involvement, the side of initial affection being more affected (table 1).

The commonest presenting complaints were related to weakness of interossei, thenar and hypothenar muscles with or without obvious wasting. In this phase, the disorder superficially resembled a lower plexus brachial lesion without sensory manifestations. An additional presenting feature in 38 patients $(37.2 \%)$ was a unilateral tremor at $6-8 \mathrm{~Hz}$, a feature well recognised in spinal muscular atrophies. Another common complaint, elicited more often by direct enquiry was muscle twitching-in 67 patients $(65 \cdot 6 \%)$. There was no fatiguability or cold paresis.

\section{Relationship to handedness}

In 27 patients, the weakness was confined to the left upper limb while in 19 the affection was more marked in the left hand and forearm (table 2). Seven of these 46 patients were left handed. When the initial affection was in the non dominant hand, presentation was
Table 2 Handedness in relation to muscle affection

\begin{tabular}{|c|c|c|c|}
\hline \multirow{2}{*}{$\begin{array}{l}\text { Affected } \\
\text { side }\end{array}$} & \multicolumn{2}{|c|}{ Handedness } & \multirow[b]{2}{*}{ Total } \\
\hline & Right & Left & \\
\hline Unilateral $_{\mathbf{L}}^{\mathbf{R}}$ & $\begin{array}{l}22 \\
12\end{array}$ & $\begin{array}{l}0 \\
5\end{array}$ & $\begin{array}{l}22 \\
27\end{array}$ \\
\hline $\begin{aligned} \text { Bilateral } \mathbf{R}>\mathbf{L} \\
\mathbf{L}>\mathbf{R}\end{aligned}$ & $\begin{array}{l}39 \\
17 \\
90\end{array}$ & $\begin{array}{r}5 \\
2 \\
12\end{array}$ & $\begin{array}{r}44 \\
1 \\
102\end{array}$ \\
\hline
\end{tabular}

delayed for 2 to 7 years, while with initial dominant affection presentation was invariably in the first year.

\section{Course}

The muscle weakness and wasting was confined to the hand of one side for 6 months to 2 years before progressing proximally to affect the forearm muscles. At about the same time, the other hand showed early evidence of weakness of intrinsic muscles with mild wasting and sometimes tremor. Several months later, fasciculation could be noted in the upper arm and occasionally (four patients) in the shoulder girdle muscles of the first affected limb and the forearm of the other. At this stage, there was a unilateral (in 69 patients) or bilateral tremor (in 33 patients). In a later phase, considerable wasting was evident in both hands with asymmetrical involvement of forearms (fig 2).

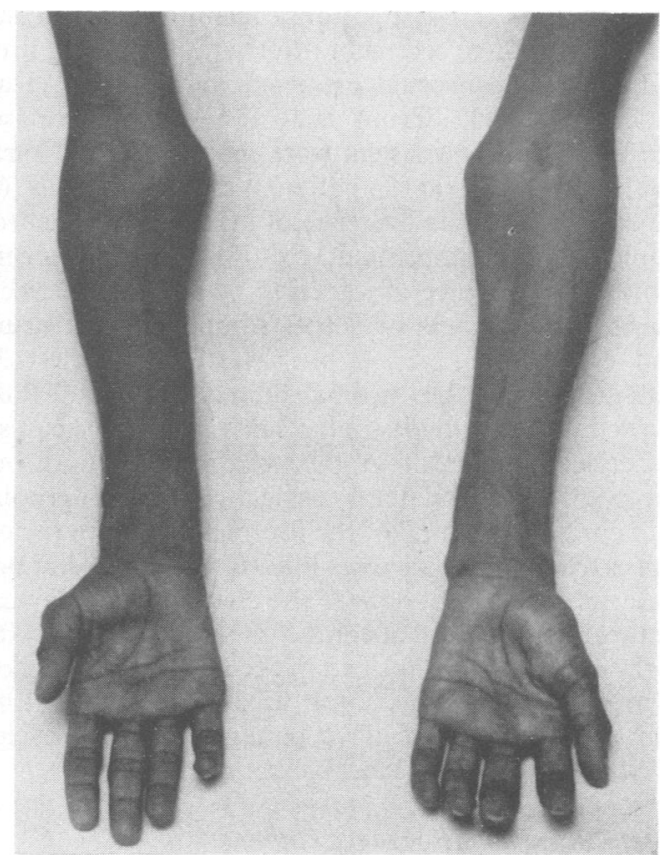

Fig 2 Wasted upper limbs, palmar view. 
Table 3 Graded EMG findings at presentation

\begin{tabular}{lrrrrrrrr}
\hline & \multicolumn{9}{l}{ Grading } & & & & \\
\cline { 2 - 8 } Muscle & $N$ & 1 & 2 & 3 & 4 & 5 & EMG \\
\hline First affected limb & 0 & 0 & 49 & 39 & 10 & 4 & 102 \\
Intrinsics & 3 & 20 & 53 & 25 & 0 & 1 & 102 \\
Forearm & 46 & 10 & 30 & 1 & 0 & 0 & 87 \\
Upper arm & & & & & & & \\
Second affected limb & 11 & 51 & 36 & 3 & 0 & 1 & 102 \\
Intrinsics & 23 & 19 & 14 & 1 & 1 & 0 & 58 \\
Forearm & 15 & 1 & 1 & 0 & 0 & 0 & 17 \\
\hline Upper arm & & & & & & & &
\end{tabular}

There was a gradient in muscle power from zero in the severely affected intrinsic muscles to four plus in the elbow flexors, with normal power in the shoulder girdle except in five patients. Upper limb reflexes, often asymmetrical, were diminished or absent depending on severity of affection, with the triceps jerk affected most and earliest, biceps and supinator jerk the least.

Clinical and electromyographic evidence suggested that the disease commenced in the motor neuron pool of one side, at the first thoracic and eighth cervical (C8T1) level and then spread upwards to involve levels up to the fifth cervical level (C5) on the same side, while involving the $\mathrm{C} 7, \mathrm{C} 8, \mathrm{~T} 1$ motor neuron pool of the opposite side. There was neither clinical nor electromyographic evidence that the disease spreads beyond the fifth cervical or first thoracic segments.

\section{Investigations}

Haematological investigations (haemoglobin, red and white cell counts, sedimentation rates, serology, urea and electrolytes, serum proteins) were normal in all patients studied. Serum enzymes (creatine kinase, aldolase, transaminases) were not elevated. Viral studies on the blood (86 patients) and spinal fluid (68 patients) showed no evidence of infection by a neurotropic virus. Complement fixation titres of serum showed no evidence of infection by mumps, measles, adenovirus, vaccinia or herpes simplex virus). Serum lead estimations carried out in 10 of the first 30 patients were within normal limits. The spinal fluid showed no abnormality in the cases studied (68 cases).

Cervical spine radiographs were normal in all but one patient with bilateral cervical ribs. Myelography with careful screening of the foramen magnum region was carried out on all cases initially (63 cases) but not undertaken later in view of the characteristic clinical picture and temporal progression. In two patients with slight dilatation of the cord in the mid cervical region at myelography, exploration was undertaken but no abnormality detected. Two patients had CT myelography without demonstrable abnormality.

Electromyographic changes (table 3)

The earliest recognisable EMG abnormality was the
Table 4 Course of disease. Follow up EMG in relation to clinical phase of disorder

\begin{tabular}{|c|c|c|c|c|}
\hline \multirow{2}{*}{$\begin{array}{l}\text { Years } \\
\text { of } \\
\text { Disease }\end{array}$} & \multirow{2}{*}{$\begin{array}{l}\begin{array}{l}\text { Clinically } \\
\text { progressive } \\
(2 I)\end{array} \\
\begin{array}{l}\text { EMG grades } \\
I-4\end{array}\end{array}$} & \multicolumn{2}{|c|}{$\begin{array}{l}\text { Clinically } \\
\text { static } \\
(25)\end{array}$} & \multirow{2}{*}{$\begin{array}{l}\text {-Total } \\
\text { Follow up } \\
\text { EMG }\end{array}$} \\
\hline & & $1-4$ & 5 & \\
\hline $\begin{array}{l}1-5 \text { years } \\
6-8 \text { years } \\
>8 \text { years }\end{array}$ & $\begin{array}{r}20 \\
1 \\
0\end{array}$ & $\begin{array}{l}5 \\
3 \\
0\end{array}$ & $\begin{array}{l}3 \\
6 \\
8\end{array}$ & $\begin{array}{r}28 \\
10 \\
8\end{array}$ \\
\hline
\end{tabular}

fragmentation of motor units leading to the presence of a high proportion of low voltage units of short duration (grade 1). In the next stage, progressive reduction in the maximum recruitment pattern seen during attempted maximum voluntary contraction was associated with the appearance of a few polyphasic units of increased voltage and duration (grade 2). At a later stage of the evolution of the disease characteristic evidence of active anterior horn cell degeneration and re-innervation was recognised by the gross reduction of recruitment pattern, leaving intact a solitary unit or two showing fasciculation potentialsthat is, polyphasic units of $10-15 \mathrm{mV}$ amplitude and duration of $10-15 \mathrm{~ms}$ firing repetitively at low frequencies (grade 3).

The terminal stages of the atrophy was indicated by the progressive fragmentation and dissolution of these giant units (grade 4). In those in whom there was no clinical progression of the disease, the EMG showed giant units without evidence of fragmentation of motor units suggestive of burnt out anterior horn cell disease similar to that seen in poliomyelitis (grade 5).

Several of the serial changes could be demonstrated to co-exist in a single patient. Sampling of the small muscles of the wasted hand showed late stages of the disease, whereas the forearm and upper arm muscles, some clinically affected, showed evidence of early changes. Evidence of progressive denervation in a single group of muscles was also obtained (in eight patients at the inception of the study) by serial sampling of these muscles over an eight to 12 months period. Sensory and motor nerve conduction studies were well within normal range in all cases.

\section{Muscle biopsy}

Muscle biopsy was carried out in the first 23 patients. Strips of moderately affected muscle, $2 \mathrm{~cm} \times 1 \mathrm{~cm}$ (usually first dorsal interosseous, palmaris longus or triceps) were examined histologically. The biopsy specimen showed atrophy of groups of muscle fibres in fasciculi. Variation in size between groups of atrophic muscle fibres constituting such groups showed features compatible with temporally dissociated involvement of motor neurons. Intramuscular nerve fibres and muscle spindles appeared normal. Once the 
clinical features, natural history, EMG abnormalities of the group as a whole were established, muscle biopsy did not appear to give additional information, apart from confirming a neuronal lesion. It was therefore not carried out in the later cases.

There have been no deaths due to the disease and no necropsy material has become available for examination from death due to other causes.

\section{Antecendent or associated factors}

Forty seven were from unskilled or semiskilled occupations, 23 were clerical workers, 12 teachers and the rest (40) still in school. Seventy seven were from the lower socio-economic classes. Only 21 had spent most of their lives in a city environment. Many males, including the schoolboys were engaged in agricultural pursuits though no specific toxic or infective factor could be determined. The body build and nutritional status were within the national norm. One patient, a 24 year old male, had poliomyelitis at the age of 6 years, with residual weakness of the legs. EMG studies showed no evidence of an active anterior horn cell lesion in the legs while the upper limbs showed the characteristic changes described earlier.

In two patients, the weakness and wasting was superimposed on the ipsilateral hand of an infantile hemiplegia.

The geographical distribution, more than two thirds from the Western and Southern provinces, appeared to be related to the referral system than a true geographical scatter.

\section{Follow up}

Only patients who have had the symptoms for at least one year and have been followed for another year were included. Of the 102 patients, 31 have been followed for more than 10 years, $\mathbf{4 2}$ for five to 10 years and the remaining 29 for 1 to 5 years. In 76 patients (75\%) there was clinical arrest of the disease within 5 years after onset, but EMG evidence of active anterior horn cell disease (stages 1-4) were seen even up to 8 years in three of the 46 patients who had a follow up EMG (table 4).

\section{Discussion}

The clinical, radiological, electromyographic and histological features are strongly in favour of a neuronal lesion and enable a clear distinction to be made from other causes of distal upper limb wasting in this age group. Distal myopathy, motor neuropathy, brachial radiculopathy and craniospinal abnormalities with syringomyelia have many differential features. The young age group, the marked asymmetry, restriction of the disease to a few cervico-dorsal segments even after many years and the characteristic clinical course help in the differentiation from the progressive muscular atrophy of classical motor neuron disease.

These patients as a group present distinctive features which merit its recognition as a distinct clinical entity. They are

1. young age group - onset between 15 and 25 years

2. marked male preponderance

3. absence of a family history or antecedent factors

4. pure motor affection confined to the upper limbs with distal onset and slow progression

5 . initial unilateral involvement with later bilateral asymmetrical affection

6. unilateral or bilateral tremor

7. clinical features of denervation including fasciculation

8. slow evolution of the disease with delayed spontaneous arrest.

9. lack of involvement of cranial nerves, lower limbs, sphincters, pyramidal tracts, sensory systems and cerebellar pathways

10. EMG evidence strongly suggestive of an initially progressive neuronal disorder with later arrest.

In the same location (Sri Lanka), the same clinical and temporal profile has not been seen in any other age group. It is unlikely that this disorder would have gone unrecognised in the past. Even if it had, the survivors of this non fatal and relatively benign disorder should have presented the arrested picture in a middle age group. It would therefore not be incorrect to consider this condition a disease entity that has appeared in Sri Lanka recently. The relatively large number seen in a short period enchances its significance.

The presence of similar but clinically distinct neurogenic muscular atrophies of the distal upper extremities confined geographically to Asia in the last 3 decades raises interesting queries particularly with regard to aetio-pathogenesis.

The incidence of other neurological disorders in the country have not altered during this period but strokes in the young ${ }^{18}$ and compressive cervical spondylotic disc disease in the young ${ }^{19}$ have been documented as interesting new clinicopathological entities, in Sri Lanka.

\section{Distal neurogenic muscular atrophies of Asia and} Australia

The first descriptions of distal juvenile neurogenic muscular atrophy of the upper limbs were from $\mathrm{Japan}^{3}$ in 1956. Further reports from $\mathrm{Japan}^{6-8}$ resembled the Sri Lankan variety in some ways but were often unilateral. The Madras variety reported by Meenakshisunderam et al ${ }^{12}$ and Jagannathan et al ${ }^{13}$ in 1971 , differed in several ways, with lower limb, brain 
stem and pyramidal tract affection. The series reported by Singh et al ${ }^{10}$ from New Delhi, on the other hand, have many similarities to our patients. Other reports from India are those of Gourie-Devi et al ${ }^{11}$ and Wadia. ${ }^{20}$ The cases reported by Loong et $a l^{21}$ from Singapore and Tan et $a^{22}$ in Malaysia, resemble those reported by Hirayama et al. ${ }^{3}$ Cases reported from Sydney ${ }^{17}$ included young as well as middle aged patients. These writers refer to previous reports of chronic spinal muscular atrophy, ${ }^{23-25}$ one with upper limb involvement as well. However, there is little justification for their view that the latter is a link between two forms of chronic spinal muscular atrophy-in the upper and lower limbs.

Upper limb distal spinal muscular atrophies outside Asia Meadows and Marsden ${ }^{24}$ in the course of a study of patients with Kugelberg-Welander syndrome recognised six cases of distal chronic spinal muscular atrophy, which apart from their symmetrical distribution also showed motor involvement of the legs, a familial incidence, absence of vibration sense and no fasciculation.

Sporadic cases with a distal upper limb affection has also been described in Denmark ${ }^{14}$ and Holland. ${ }^{16}$ Osuntokun et $a l^{26}$ in a prospective study of 92 Nigerians with motor neuron disease described 10 patients with predominant distal upper limb affection. However, mean age of onset was $39.9 \mathrm{yr}$ (in the 7 males) and $33 \mathrm{yr}$ (in the 3 females). The progression was rapid and there were two deaths.

\section{Nomenclature}

The entity described in this paper, while having many distinctive features, resembles the juvenile spinal muscular atrophies in age of onset, course and prognosis, while it resembles the progressive muscular atrophy variety of motor neuron disease in the distribution of muscle involvement. Distal muscle affection is rare in spinal muscular atrophy while it is commoner than the proximal in motor neuron disease.

When we first described this condition in $1976,{ }^{9}$ only two of the 33 patients showed arrest of the condition (forme fruste variety) and termed it young motor neuron disease but emphasised that it was distinctly different from the Madras variety of juvenile motor neuron disease. We have subsequently preferred to use the term juvenile distal spinal muscular atrophy, which aptly describes the clinical presentation.

\section{Aetiology considerations for Asian neurogenic muscular atrophy}

A recent necropsy study of the Japanese variety has confirmed the pure neuronal nature of the disease. ${ }^{27}$ The causative factors so far considered in the Asian non familial neurogenic muscular atrophy include indirect trauma to the cervical spine, unknown viral infection, atypical poliomyelitis and metabolic abnormalities. These suggestions do not satisfactorily explain why these self limiting neuronal disorders have affected predominantly males in a specified geographical region only during the past three decades. Nor is there an explanation of the anatomical localisation of the lesion to cervical and upper thoracic segments.

The clustering of cases in Japan and Asia prompts one to consider ethno-cultural or racial factors in aetio-pathogenesis. A vertical genetic factor of low penetrance could be unmasked by an environmental factor-infective, toxic, or nutritional, as in some other diseases.

An infective cause, affecting healthy young males predominantly, progressing for several years and then arresting spontaneously, is difficult to explain. However, a Sri Lankan male migrating to Los Angeles at the age of 5 years developing the disease at 15 years make us retain the possibility of a slow viral infection.

Cycas circinalis, a common fern found in many parts of Sri Lanka, is known to contain an uncommon amino acid beta-N-methylamino-L-alanine (BMAA) which has been experimentally shown to produce anterior horn cell degeneration in primates. ${ }^{28}$ The powder obtained from the dried fruit of Cycas circinalis is used as a cheap stimulant but none of our patients admitted its regular or frequent use.

Absorption of toxins through the skin damaging the nervous system and even producing respiratory failure requiring ventilation is documented. ${ }^{29}$ Toxic substances could also be absorbed through the skin of the hands and travel along the perineural vascular and lymphatic pathways. Their natural destination would be the lower cervical and upper thoracic cord. In Sri Lanka, as in many of the other Asian countries, handling with the bare hands is a common practice. The accelerated programmes for agricultural and industrial development in the Asian region have led to exposure of manual workers in particular to many potentially toxic substances. The possible relationship of this to the temporal clustering of cases of Asian neurogenic muscular atrophy is worthy of consideration. It is interesting to note that in Japan, where post war development in agriculture and industry preceded that in most other Asian countries, an Asian variety of neurogenic muscular atrophy appeared about 15 years earlier. More than three fourths of our patients were from the lower social class who would be engaged in manual work on a full or part time basis. The arrest of the disease within about 5 years may be due to the fact that the disease process itself makes it difficult for the individual affected to use his hands, due to the muscle atrophy. This would prevent further access of toxic substances, and may provide an explanation for the apparently spontaneous arrest of the disease which has been consistently observed. 


\section{References}

1 Wohlfart G, Fex J, Eliasson S. Hereditary proximal spinal muscular atrophy-a clinical entity simulating progressive muscular atrophy. Acta Psychiat Scand 1955;30:395-406.

2 Kugelberg E, Welander L. Heredofamilial juvenile muscular atrophy simulating muscular dystrophy. Arch Neurol Psychiatr 1956;75:500-9.

3 Hirayama K, Tokokura Y, Tsubaki T. Juvenile muscular atrophy of unilateral upper extremity-a new clinical entity. Psychiatry, Neurology (Japan) 1959;61:2190-7.

4 Hirayama K, Tsubaki T, Tokokura Y, Okinaka S. Juvenile muscular atrophy of unilateral upper extremity. Neurology 1963;13:373-80.

5 Hirayama K. Juvenile non progressive muscular atrophy localised in hand and forearm-observation in 38 cases. Clinical Neurology (Tokyo) 1972;12:313-24.

6 Ando K, Iida M, Takagi S, Yamamoto K, Sobue T, Munro Y. Glove and stocking muscular atrophy. Brain Nerve 1963; 155: 1028-33.

7 Hashimoto O, Asada M, Ohta M, Kuroiwa Y. Clinical observation of juvenile non progressive muscular atrophy localised in hand and forearm. $J$ Neurol 1976;211:105-10.

8 Sobue I, Saito N, Iida M, Ando K. Juvenile type of distal and segmental muscular atrophy of upper extremities. Ann Neurol 1978;3:429-32.

9 Peiris JB, Seneviratne KN, Wickremasinghe HR, Boralessa $H$, Chandrasekara MA. Motor neurone disease in the young. Institute of Neurology (Madras) Proceedings 1976;6:160-8.

10 Singh N, Sachdev KK, Susheela AK. Juvenile muscular atrophy localised to arms. Arch Neurol 1980;40:297-9.

11 Gouri-Devi M, Suresh TG, Shankar SK. Arch Neurol 1984;41: 388-94.

12 Meenakshisunderam E, Jagannathan K, Ramamurthi B. Neurology (India) 1970;18(suppl 1):109-12.

13 Jagannathan K. Juvenile motor neurone disease. In: Spillane JD, ed. Tropical Neurology Oxford University Press 1973:127-30.

14 Pilgaard S. Unilateral juvenile muscular atrophy of upper limbs. Acta Orthop Scand 1968;39:327-31.

15 Meadows JC, Marsden CD, Harriman DGF. Chronic spinal muscular atrophy in adults. Journal of Neurological Science
1969;9:551-66.

16 Campernolle T. A case of juvenile muscular atrophy confined to one upper limb. European Neurology 1973;10:237-42.

17 O'Sullivan DJ, McLeod JG. Distal chronic spinal muscular atrophy involving the hands. J Neurol Neurosurg Psychiatry 1978;41:653-8.

18 Peiris JB, Wickremasinghe HR. Transient Emboligenic AortoArteritis. (T.E.A.)-a noteworthy new entity in the young stroke patient. In: Gillingham J, Mawdsley C, Williams I, eds. Stroke (1976) Churchill.

19 Selladurai BM, Peiris JB. Cervical spondylotic myelopathy in the young. Ceylon Medical Journal 1981;26:59-63.

20 Wadia NH. In: Spillane JD, ed. Tropical Neurology, Oxford University Press 1973.

21 Loong SC, Yap MHL, Nei IP. An unusual form of motor neurone disease. Proc. 10th Singapore-Malaysia Congress of Medicine Acad. Med Singapore 1975;10:315-9.

22 Tan CT. Juvenile muscular atrophy of distal upper extremity. $J$ Neurol Neurosurg Psychiatry 1985;48:285-6.

23 Dyck PJ, Lambert EH. Lower motor and primary sensory neurone disease with peroneal muscular atrophy. Arch Neurol 1968; 18:619-25.

24 Meadows JC, Marsden CD. A distal form of chronic spinal muscular atrophy. Neurology 1969;19:53-9.

25 McLeod JG, Prineas JW. Distal type of chronic muscular atrophy. Brain 1971;94:703-14.

26 Osuntokun BS, Adeuja AOG, Bademosi O. Prognosis of motor neurone disease in Nigerian Africans-a prospective study of 92 patients. Brain 1974;97:385-94.

27 Hirayama K, Tomonaga M, Kitano K, Yamada T, Kojima S, Arai K. Focal cervical poliopathy causing juvenile muscular atrophy of distal upper extremity: a pathological study. J Neurol Neurosurg Psychiatry 1987;50:285-90.

28 Spencer PS, Schaumburg HH. Experimental models of primary axonal disease induced by toxic chemicals. In: Dyck PJ, Thomas PK, Bunge RP eds. Peripheral Neuropathy 2nd ed, Philadelphia. WB Saunders, vol 1;1984:636-49.

29 Peiris JB, Fernando R, De Abrew K. Respiratory failure from severe organophosphate toxicity due to absorption through the skin. Forensic Sci Int 1987;36:1-3. 